\title{
A Systematic Review and Meta-Analysis of the Safety and Effectiveness of Tenecteplase Versus Alteplase in Treatment of Patients with ST-Elevation Myocardial Infarction
}

\author{
Salman Bashzar ${ }^{1}$ (D), Shekoufeh Nikfar ${ }^{2}$ (D) Asma Sabermahani $^{1 *(i)}$
}

1. Student Research Committee, School of Health Management and Information Sciences, Kerman University of Medical Sciences, Kerman, Iran

2. Dept. of Pharmacoeconomics, Faculty of Farmacy, Tehran University of Medical Sciences, Tehran, Iran

\begin{tabular}{|c|c|}
\hline Article Info & ABSTRACT \\
\hline doi $10.30699 / j a m b s .28 .130 .265$ & $\begin{array}{l}\text { Background \& Objective: If primary angioplasty is not available, thrombolytic } \\
\text { therapy is an appropriate option for the treatment of acute myocardial infarction }\end{array}$ \\
\hline $\begin{array}{l}\text { Received: 2020/01/22; } \\
\text { Accepted: 2020/09/16; } \\
\text { Published Online: } 30 \text { Sep 2020; }\end{array}$ & $\begin{array}{l}\text { the safety and effectiveness of tenecteplase (TNKase) vs. alteplase in the treatment } \\
\text { of ST-elevation myocardial infarction (STEMI). }\end{array}$ \\
\hline \multirow[t]{2}{*}{$\begin{array}{l}\text { Use your device to scan and read the } \\
\text { article online }\end{array}$} & $\begin{array}{l}\text { Materials \& Methods: PubMed, Cochrane Library, and Web of Science were } \\
\text { searched for the safety and clinical effectiveness of TNKase vs. alteplase, and a } \\
\text { manual search was performed among the American, European, and Iranian } \\
\text { cardiovascular journals. Randomized clinical trials (RCTs) that included comparisons } \\
\text { of TNKase with alteplase alone or with other drugs in STEMI patients published in } \\
\text { English, Persian, and Korean languages were included. Two authors independently } \\
\text { assessed the eligibility and quality of RCTs. Finally, the data were analyzed in Review } \\
\text { Manager version 5.3. }\end{array}$ \\
\hline & $\begin{array}{l}\text { Results: There was no statistically significant difference between TNKase and } \\
\text { alteplase in the risk of } 30 \text {-day mortality (RR }=1.01 ; 95 \% \text { CI: } 0.89-1.13 ; P=0.82) \text {. The }\end{array}$ \\
\hline \multirow{2}{*}{$\begin{array}{l}\text { Corresponding Information: } \\
\text { Asma Sabermahani, } \\
\text { Student Research Committee, School of } \\
\text { Health Management and Information } \\
\text { Sciences, Kerman University of Medical } \\
\text { Sciences, Kerman, Iran }\end{array}$} & $\begin{array}{l}\text { minor bleeding was similar in AMI patients treated with both drugs. TNKase was } \\
\text { associated with a statistically significant reduction of total bleeding }(P=0.0003) \text { and } \\
\text { major bleeding }(P=0.0003) \text {. }\end{array}$ \\
\hline & $\begin{array}{l}\text { Conclusion: In comparison with alteplase, TNKase is recommended due to its } \\
\text { easier use and higher safety in reducing the risk of bleeding. }\end{array}$ \\
\hline E-Mail: sabermahany@gmail.com & $\begin{array}{l}\text { Keywords: Thrombolytic therapy, Acute myocardial infarction, ST-elevation } \\
\text { Myocardial infarction. }\end{array}$ \\
\hline
\end{tabular}

\section{Introduction}

Cardiovascular disease is the most common cause of death in most countries. It causes complications, significant disability, and loss of productivity, and imposes a considerable financial burden on healthcare systems $(1,2)$. Standard treatment for ST-elevation myocardial infarction (STEMI) is an immediate reestablishment of the blood flow to closed vessels (reperfusion), which aims to prevent myocardial necrosis and save myocardial infarction (MI) in order to reduce the incidence of heart failure and eventually increase the patient's survival $(3,4)$.

Reperfusion is performed with two methods of fibrinolysis and angioplasty. Fibrinolytic drugs are divided into two categories of fibrin-specific and fibrin-nonspecific thrombolytic agents $(5,6)$. Fibrin alteplase is given as a bolus dose of $15 \mathrm{mg}$ and then a dose of $50 \mathrm{mg}$ intravenously in the first 30 minutes, followed by $35 \mathrm{mg}$ in the next 60 minutes, with a halflife of $\sim 5$ minutes. As the half-life is very short, it is rapidly expelled from the body (7) and the rest of the tenecteplase is leaked from tissue plasminogen activator (tPA), which has a longer half-life (5, 8-10). The fewer complications and possibility of quick and easy administration have rendered fibrin alteplase as a preferred drug. It is given as a single dose of intravenous bolus based on patient weight $(5,8-10)$.

Plasminogen activators restore the normal coronary flow in 50-60\% of STEMI patients $(11,12)$. The successful use of fibrinolytic drugs increases the chance of survival for patients, which can remain for many years. However, an important variable in the success of these factors is the onset of the signs of the disease and the prescription of the medication. Moreover, these factors will have the greatest 
impact when 30 minutes or less has passed from the onset of clinical symptoms until the injection (12).

There is a relatively large body of evidence (13-27) on the effectiveness of thrombolytic drugs. Moreover, there are various studies suggesting that the effectiveness and cost-effectiveness of thrombolytic drugs are different, and may differ from country to country. Some countries do not allow the import of newer or even older drugs (28) because these drugs can exert different effects in terms of safety and effectiveness, and also have different costs. Since health expenditure is globally increasing following the development of technology, health systems cannot provide all services to all members of the community. Hence, the governments must decide which drugs to be validated or covered by insurance companies. Alteplase is on the lists of both Iranian medicines and insurance companies. However, tenecteplase, which has recently been added to this list, has not entered the country yet. Thus, it is not covered by the insurance companies. It seems that the financial burden is high due to the high incidence of MI in Iran. Studies on the safety and clinical effectiveness of tenecteplase and alteplase have reported different results. Accordingly, this meta-analysis attempted to determine whether thrombolysis with tenecteplase has better safety and clinical effectiveness outcomes than with alteplase in patients with STEMI.

\section{Materials and Methods}

\section{Search Methods}

Clinical trials investigating the tenecteplase regime compared to alteplase (alone or in combination with other drugs) were investigated. In order to collect data, the databases of MEDLINE, Cochrane Library, and Web of Science were searched for relevant studies from February 1980 up to June 2017 by using different strategies. The search strategy was transparent and incorporated sensitivity by combining the keywords of myocardial infarction, heart infarction, STEMI, STsegment elevation myocardial infarction, AMI, thrombolysis, tPA, alteplase, Tenecteplase (sold under the trade names TNKase and Metalyse) is an enzyme used as a thrombolytic drug. Other medications and brand names were also included in the search and used for most studies (Free Text, MeSH). The search was limited to articles published in English, Persian, and Korean languages. After the electronic search, the list of resources was also searched manually by the researcher to collect any missed data. Subsequently, websites of Iranian and American cardiovascular associations and some other countries were reviewed. In addition, to find gray literature, congress and seminar articles were also searched. After completing the search and removing duplicate titles and abstracts, all the published articles were inputted in EndNote version 17.

\section{Inclusion and Exclusion Criteria}

The main criteria for selecting the papers were: a) being randomized clinical trials (RCTs) or controlled clinical trials (CCTs), b) studies comparing TNKase with alteplase alone or with other drugs in STEMI patients, and c) being written in English, Persian, or Korean languages. This review focused on the clinical outcomes, as described below. The primary outcomes consisted of mortality, reinfarction, cardiogenic shock, bleeding, stroke, and intracranial hemorrhage (ICH). The secondary outcomes included TIMI grade 3 flow, TIMI grade 2/3 flow, nonfatal cardiac events, STsegment resolution $>50 \%$, reischemia, heart failure, left ventricular function, allergies, anaphylaxis, and reperfusion. Articles that did not meet the above conditions were excluded.

\section{Quality Assessment}

Two reviewers independently assessed the methodological quality of the included studies using the Jadad scale for reporting RCTs and the standard method recommended by the Cochrane Institute. Also, the Cochrane EPOC Group's risk assessment checklist was employed to assess the risk of bias in the selected studies.

\section{Data Extraction}

The data were extracted using the Cochrane Data Extraction Form (RCTs and non-randomized controlled studies (NRSs)).

\section{Statistical Methods:}

The statistical tests were performed in Review Manager version 5.3 and STATA version 11. Treatment effects were presented using the risk ratio (RR) with 95\% confidence intervals (CIs) and a fixed-effects model. The Mantel-Haenszel statistical method was adopted to analyze the data. Heterogeneity was assessed and reported quantitatively using the $\mathrm{I}^{2}$ test. Analysis of data included primary and secondary outcomes.

\section{Results}

Based on PICOD (population, intervention, comparison, outcome, design), as well as inclusion and exclusion criteria, a total of 8,004 articles were searched via a search strategy. Then, the studies were inputted in EndNote version 17 and, initially, 5,647 duplicate records were removed from the search results. Finally, seven reports from five RCTs, including those by Van De Werf (1999) (6), Van De Werf (2001) (29), Sinnaeve (2003) (30), Binbrek (2004) (31),Liang (2007) (28), Cannon (1998) (32), and Jeong (2003) (33) met the inclusion criteria (Figure 1). All the reports were in English, except for one report that was in Korean (33). Overall, there were 18,265 participants in the five RCTs (Table 1). 


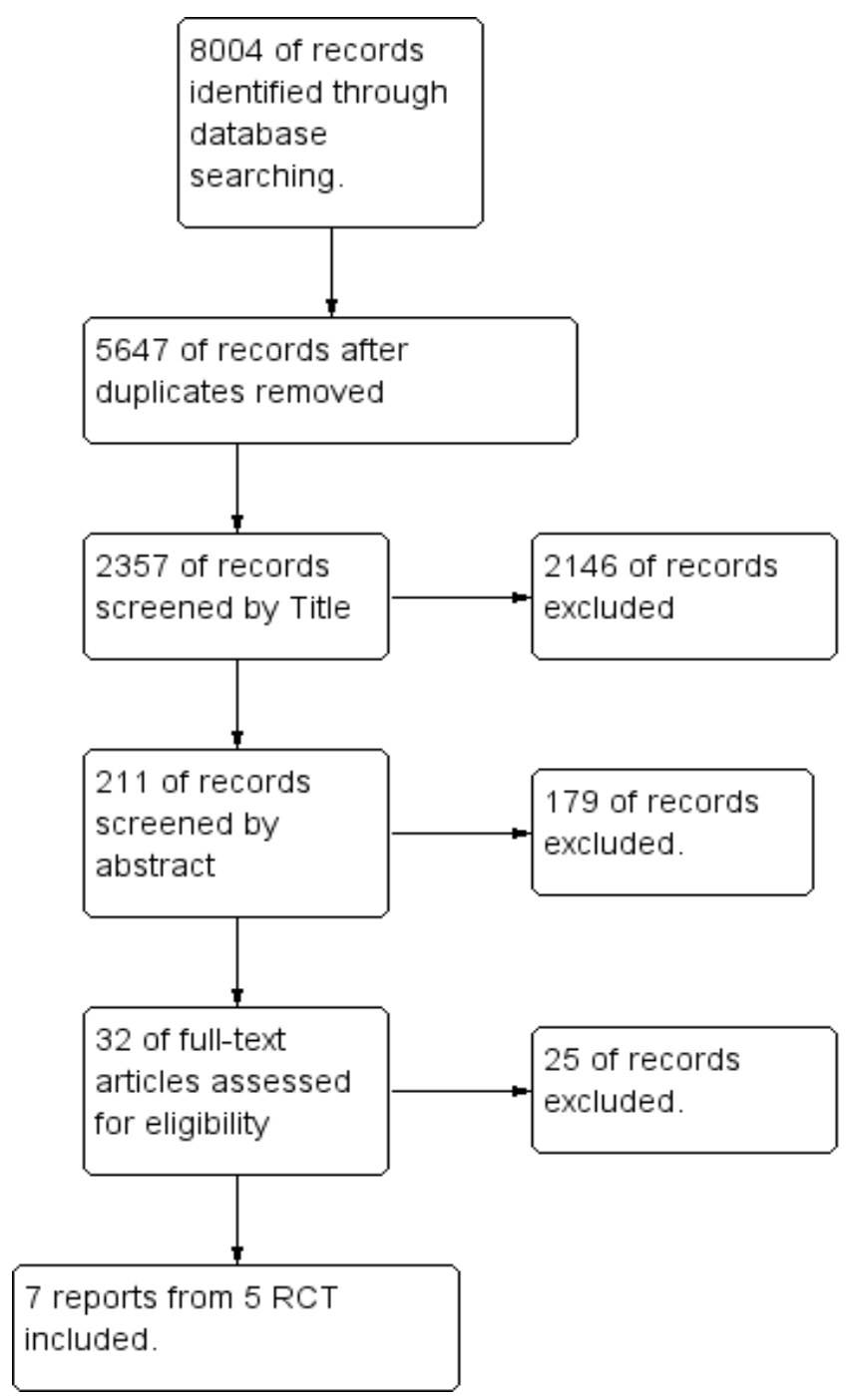

Figure 1. PRISMA flowchart

Table 1. Characteristics of the reviewed studies

\begin{tabular}{|c|c|c|c|c|c|c|c|}
\hline Characteristics & \multicolumn{7}{|c|}{ TNK-t-PA vsrt-PA } \\
\hline Study name & $\begin{array}{l}\text { Van De } \\
\text { Werf }\end{array}$ & $\begin{array}{l}\text { Van De } \\
\text { Werf }\end{array}$ & Sinnaeve & Binbrek & Liang & Cannon & Jeong \\
\hline Year & 1999 & 2001 & 2003 & 2004 & 2007 & 1998 & 2003 \\
\hline No. of patient & 16,949 & 16,949 & 15,724 & 266 & 110 & 886 & 54 \\
\hline Study design & \multicolumn{7}{|c|}{$\mathrm{RCT}$} \\
\hline $\begin{array}{c}\text { Inclusion } \\
\text { criteria }\end{array}$ & \multicolumn{7}{|c|}{ STEMI } \\
\hline TNK-t-PA dose & \multicolumn{5}{|c|}{$\begin{array}{c}30 \mathrm{mg} \text { if }<60.0 \mathrm{~kg}, 35 \mathrm{mg} \text { if } 60.0-69.9 \mathrm{~kg}, 40 \mathrm{mg} \text { if } 70.0-79.9 \mathrm{~kg}, 45 \mathrm{mg} \text { if } 80.0- \\
89.9 \mathrm{~kg} \text {, and } 50 \mathrm{mg} \text { if } \geq 90.0 \mathrm{~kg}\end{array}$} & $\begin{array}{l}\text { TNK-tPA } 30 \\
\mathrm{mg}, 40 \mathrm{mg} \\
\text { and } 50 \mathrm{mg}\end{array}$ & $\begin{array}{l}25-50 \mathrm{mg} \\
\text { weight } \\
\text { adjusted }\end{array}$ \\
\hline $\mathrm{t}-\mathrm{PA}$ dose & \multicolumn{7}{|c|}{$\begin{array}{l}\text { Alteplase was given as a } 15-\mathrm{mg} \text { bolus followed by an infusion of } 0.75 \mathrm{mg} / \mathrm{kg} \text { (to a maximum of } \Delta \cdot \mathrm{mg} \text { ) over } 30 \\
\text { minutes and an infusion of } 0.5 \mathrm{mg} / \mathrm{kg} \text { (to a maximum of } 35 \mathrm{mg} \text { ) over } 60 \text { minutes. }\end{array}$} \\
\hline Follow up & 30 days & 1 year & 1 year & 30 days & 30 days & 30 days & 30 days \\
\hline Journal & $\begin{array}{l}\text { The } \\
\text { LANCET }\end{array}$ & $\begin{array}{l}\text { European } \\
\text { heart } \\
\text { Journal }\end{array}$ & $\begin{array}{l}\text { American } \\
\text { heart Journal }\end{array}$ & $\begin{array}{l}\text { The American } \\
\text { Journal of } \\
\text { cardiology }\end{array}$ & $\begin{array}{l}\text { Journal of } \\
\text { Geriatric } \\
\text { Cardiology }\end{array}$ & $\begin{array}{l}\text { American heart } \\
\text { Journal }\end{array}$ & $\begin{array}{l}\text { Korean } \\
\text { Circulation } \\
\text { Journal }\end{array}$ \\
\hline
\end{tabular}


In all the studies, the dosage was based on standards of prescription and patient weights. Only in one study by Cannon (32), tenecteplase with three doses of 30, 40, and $50 \mathrm{mg}$ was prescribed. Also, Van De Werf (29) and Sinnaeve (30) performed one-year followups that could not be included in the meta-analysis.

The quality assessment of the studies was performed using the Jadad checklist according to which three studies (Liang (2007) (28), Cannon (1998) (32), and Werf (1999) (6)), two studies (Werf (2001) (29) and Sinneve (2003) (30)), and two studies (Binbrek (2004) (31) and Jeong (2003) (33)) obtained scores of 5,4 , and 3 , respectively. All clinical trials meeting the inclusion criteria were included and were generally of high and acceptable quality (Figures 2 and $\underline{3}$ ).

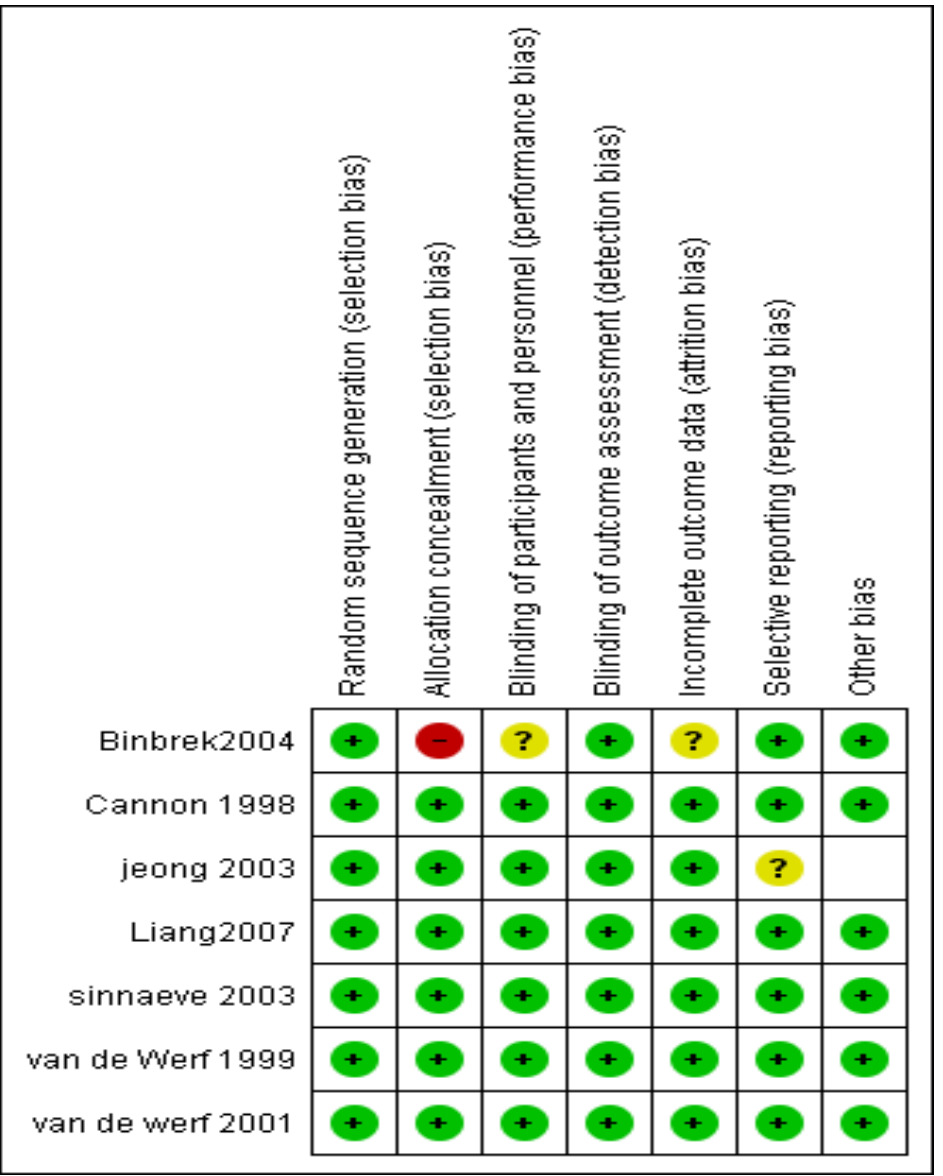

Figure 2. A summary of the risk of bias in the reviewed studies

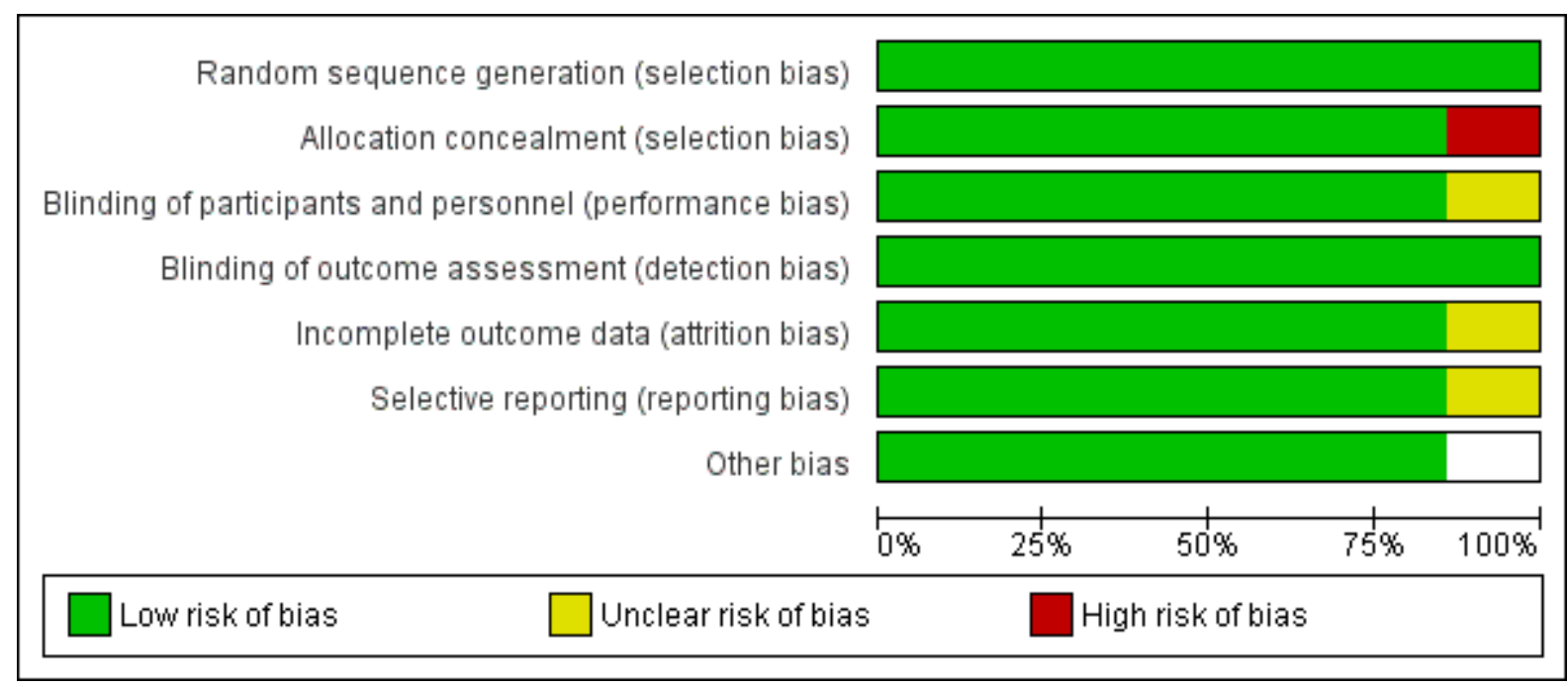




\section{Figure 3. Representation of the risk of bias in the reviewed studies}

Six studies (1- 6) reported mortality outcome, one of which (ASSENT-2) was published in two reports, one reporting mortality in the one-year follow-up and the other reporting 30-day mortalities. Four studies $(6,28,31,33)$ reported a 30 -day mortality rate with a sample of 17,379 subjects meeting the meta-analysis criteria; this suggested that the studies were homogeneous with homogeneity of zero $(P=0.58)$, and it was possible to combine the results.
There were records of $535(6.2 \%)$ and $529(6.1 \%)$ deaths among 86,776 and 8703 cases who had received tenecteplase and alteplase, respectively, with a similar 30 -day mortality $(\mathrm{RR}=1.01 ; 95 \% \mathrm{CI}$ : $0.89-1.13 ; P=0.82$ ) (Figure 4). Furthermore, the results of the sensitivity analysis showed that the study by Werf (1999) (6) had the highest effect on the final results, and the value of RR did not change significantly by eliminating other studies.

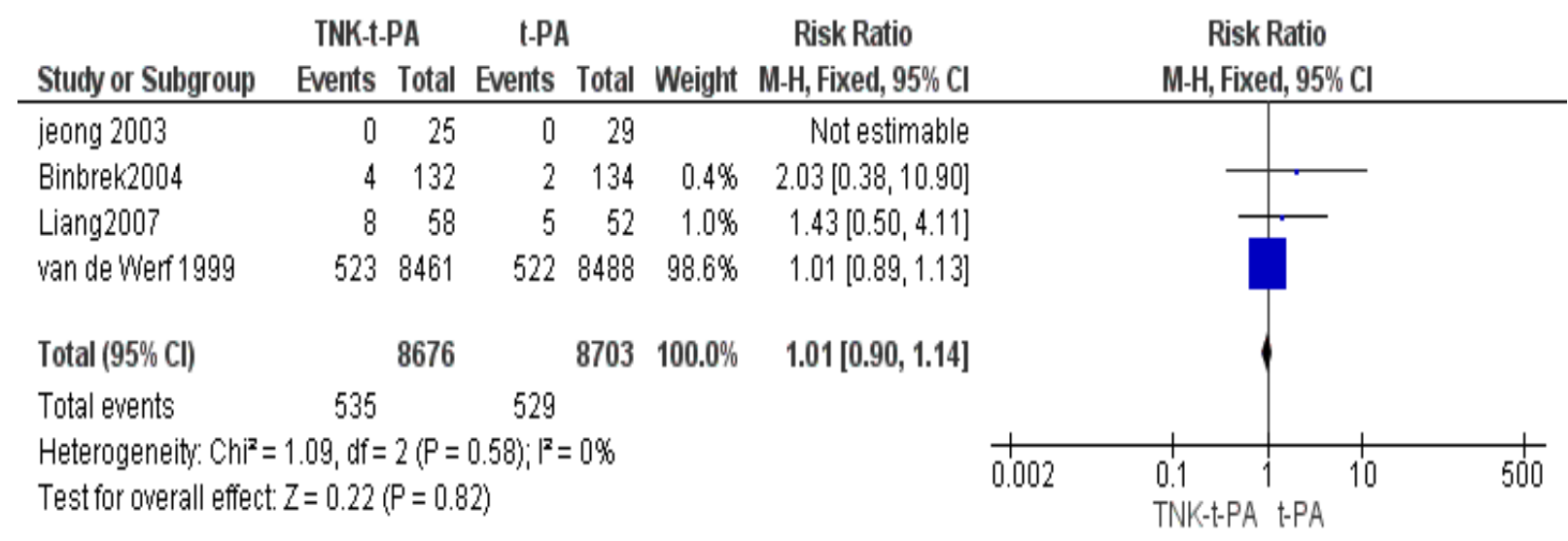

Figure 4. Forest plot of comparing 30-day mortality by TNK-t-PA vs. t-PA

\section{Reinfarction}

Three studies $(6,31,32)$ reported reinfarction in patients treated with two regimes. Two studies $(6,31)$ conducted on 17,215 participants were also included in the meta-analysis. The results revealed that 30-day reinfarction was similar in the two groups $(R R=1.07$; 95\% CI: $0.92-1.24 ; \quad P=0.36)$, and there were no statistically significant differences (Figure 5). Cannon (1998) (32) presented evidence that reinfarction occurred in $5.4 \%$ of all the participants, with $5.2 \%$, $6.5 \%$, and $2.6 \%$ for patients receiving 30,40 , and 50 $\mathrm{mg}$ of tenecteplase, respectively, and $5.7 \%$ for those consuming alteplase. No significant difference was found in the incidence of reinfarction among patients treated with tenecteplase and alteplase.

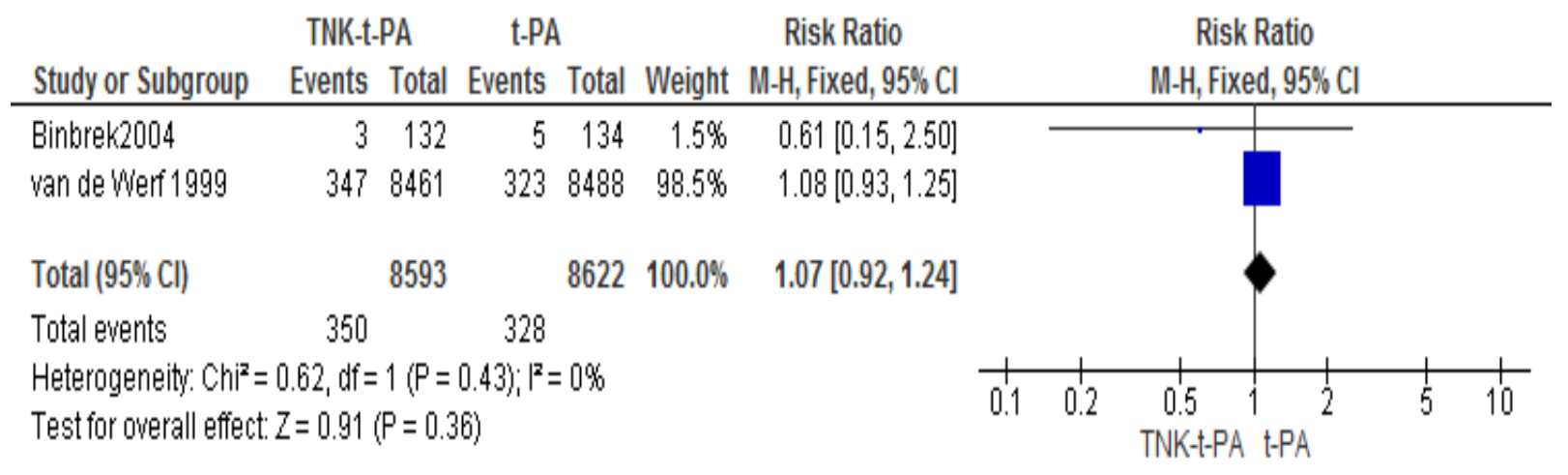

Figure 5. Forest plot of comparing reinfarction by TNK-t-PA vs. t-PA

\section{Cardiogenic shock}

There were three reports $(6,31,32)$ on cardiogenic shock following treatment with both drugs, of which two studies (Binbrek (2004) (31) and Werf (1999) (6)) with a sample size of 17,215 were included in the metaanalysis after a heterogeneity review. A total of 330 $(3.8 \%)$ and $340(3.9 \%)$ cases of cardiogenic shock occurred in patients receiving tenecteplase and alteplase, respectively, with similar occurrence in the two groups (RR=0.97; 95\% CI: 0.84-1.13, $P=0.73$ ) (Figure 6). Cannon (1998) (32) also reported differences of $2.6 \%, 3.2 \%$, and $1.3 \%$ at doses of 30,40 , and $50 \mathrm{mg}$, respectively for tenecteplase recipients, and 
$4.1 \%$ for alteplase consumers, which did not show a statistically significant difference.
TNK-t-PA
t-PA
Risk Ratio
Risk Ratio

Study or Subgroup Events Total Events Total Weight M-H, Fixed, 95\% Cl

M-H, Fixed, $95 \% \mathrm{Cl}$

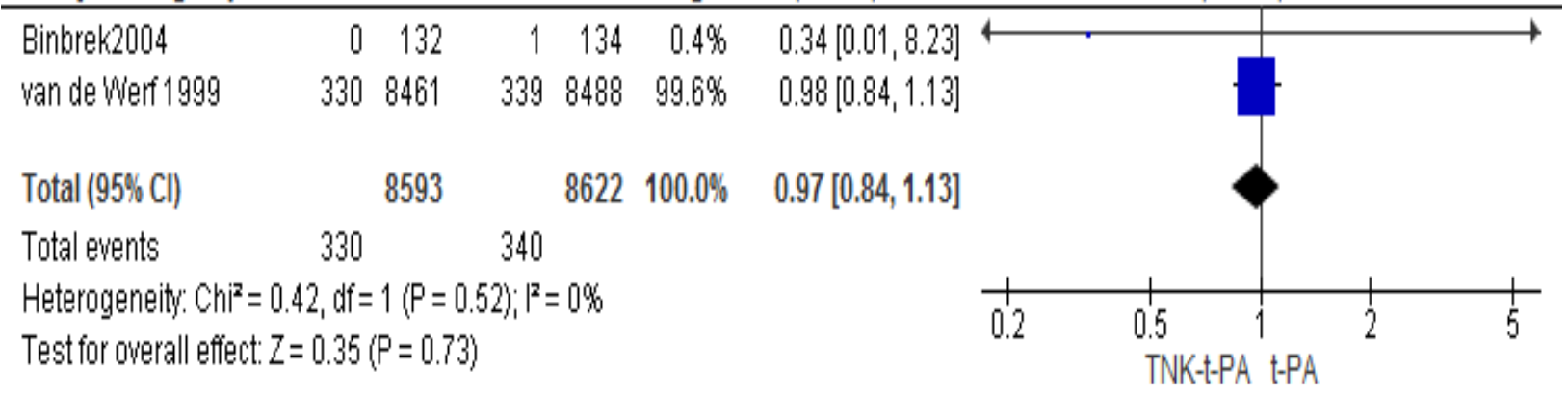

Figure 6. Forest plot of comparing cardiogenic shock by TNK-t-PA vs. t-PA

\section{Bleeding}

Five studies $(6,28,29,31,32)$ reported bleeding events, of which four trials reported bleeding events during a 30-day period, and one study observed bleeding in the second report (ASSENT-2), particularly in subgroups. Three studies of major bleeding outcomes with a sample size of 17,325 were included in the metaanalysis. The measurement of heterogeneity between studies using the ${ }^{2}$ test revealed that the studies were homogeneous (heterogeneity $=14 \%$ ), which was not considered relevant by the Cochrane guidebook $(P=0.31)$, allowing the combination of results. The results of the meta-analysis $(\mathrm{RR}=0.92 ; 95 \% \mathrm{CI}$ : 0.87 $0.96, P=0.0003$ ) indicated that overall bleeding was not the same in the two groups receiving tenecteplase and alteplase, and the difference was in favor of the group receiving tenecteplase. In other words, patients receiving tenecteplase were better than those treated by alteplase for bleeding (Figure 7).

For major bleeding events, the results indicated that major bleeding was not the same in the two groups receiving tenecteplase and alteplase, and the difference (RR=0.79; 95\% CI: $0.69-0.99, P=0.0002$ ) was to the benefit of the tenecteplase-treated group. In other words, patients receiving tenecteplase were in better conditions than those consuming alteplase in terms of major bleeding outcomes. Also, two studies by Liang (2007) (28) and Werf (1999) (6) with 170,59 participants reporting minor bleeding events were included in the meta-analysis. According to the results (Figure 7), the outcome of minor bleeding was similar in the two groups receiving the two drugs $(R R=0.95$; 95\% CI: $0.87-1.00, P=0.06)$.

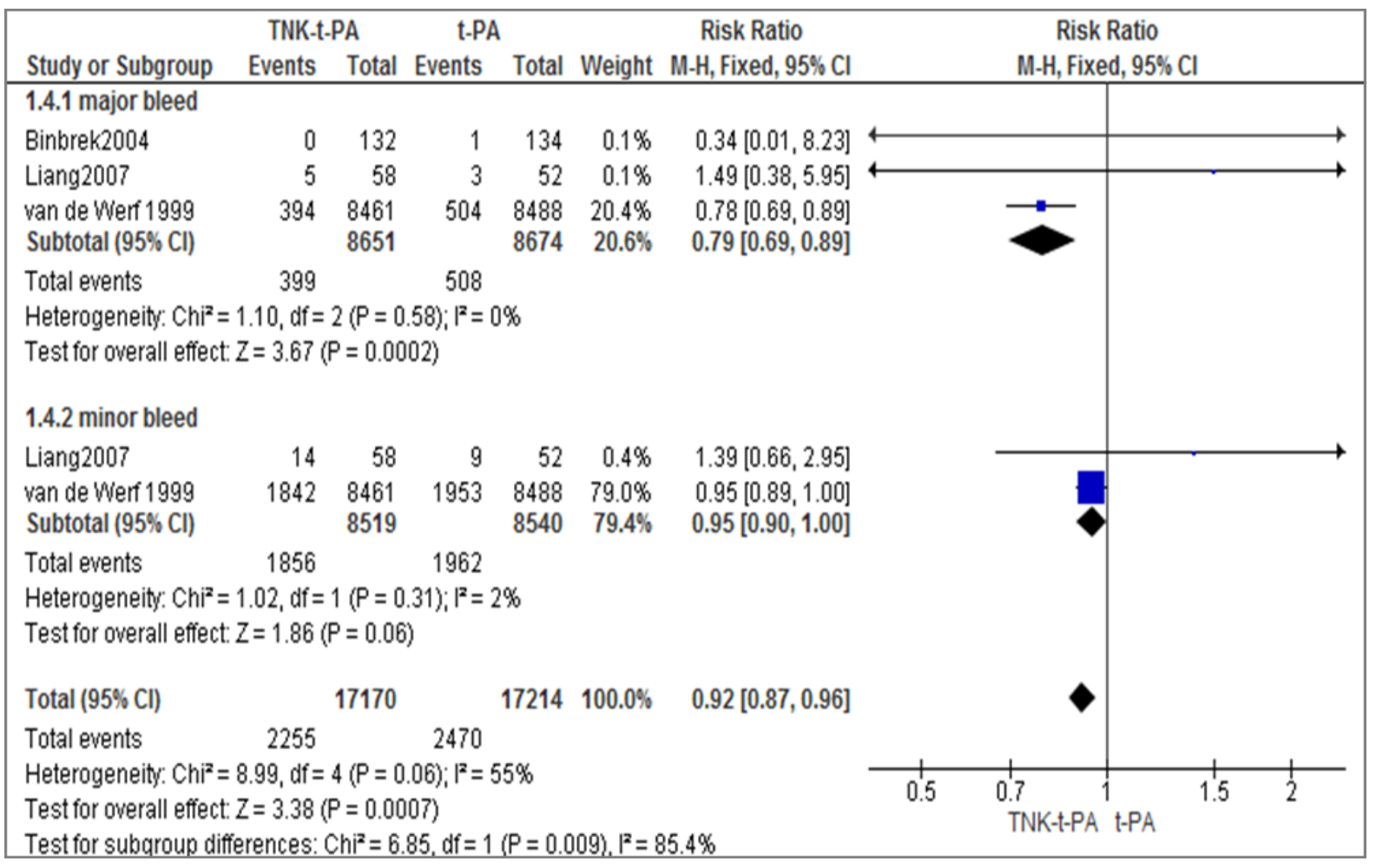




\section{Figure 7. Forest plot of comparing major and minor bleeding by TNK-t-PA vs. t-PA}

\section{Intracranial hemorrhage (ICH)}

Three studies $(6,28,32)$ reported ICH, two of which $(6,28)$ with 17059 participants were included in the metaanalysis. The studies were homogeneous $(P=0.63)$ and could be combined based on the results of the heterogeneity measured by the $\mathrm{I}^{2}$ test (Figure 8$)$. ICH was similar in both groups receiving tenecteplase and alteplase, and there was no statistically significant difference between the two groups $(\mathrm{RR}=1.00 ; 95 \% \mathrm{CI}$ : 0.74-1.36; $P=0.99$ ) (Figure 8).

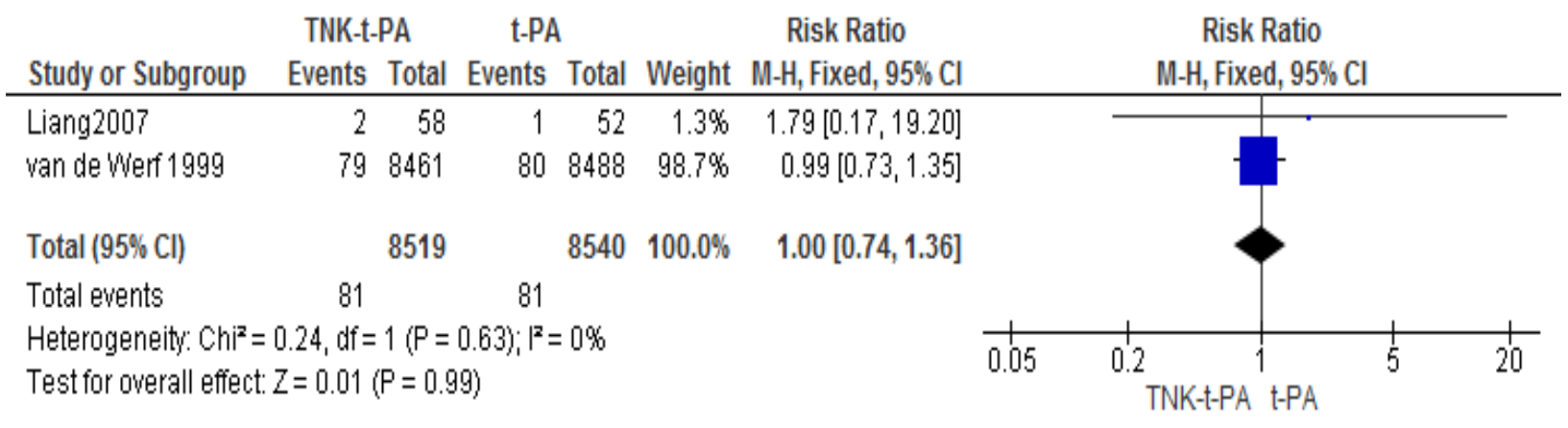

Figure 8. Forest plot of comparing ICH at 30 days by TNK-t-PA vs. t-PA

\section{Stroke}

From three reports $(6,28,32)$ of stroke events, two $(6,28,33)$ studies with a sample size of 17,059 were incorporated in the meta-analysis (Figure 9). The combined results of the studies demonstrated that the outcome of stroke was similar in the two groups receiving tenecteplase and alteplase, and there was no statistically significant difference between the two groups (RR=1.09; 95\% CI: 0.87-1.36, $P=0.47)$.

\begin{tabular}{|c|c|c|c|c|c|c|c|c|c|}
\hline Study or Subgroup & $\begin{array}{l}\text { TNK-t- } \\
\text { Events }\end{array}$ & $\begin{array}{l}\text { PA } \\
\text { Total }\end{array}$ & $\begin{array}{l}\text { t-PA } \\
\text { Events }\end{array}$ & Total & Weight & $\begin{array}{l}\text { Risk Ratio } \\
\text { M-H, Fixed, } 95 \% \mathrm{Cl}\end{array}$ & & $\begin{array}{c}\text { Risk Ratio } \\
\text { M-H, Fixed, } 95 \% \mathrm{Cl}\end{array}$ & \\
\hline Liang2007 & 3 & 58 & 1 & 52 & $0.7 \%$ & $2.69[0.29,25.06]$ & & & \\
\hline van de Werf 1999 & 151 & 8461 & 141 & 8488 & $99.3 \%$ & $1.07[0.86,1.35]$ & & & \\
\hline Total $(95 \% \mathrm{Cl})$ & & 8519 & & 8540 & $100.0 \%$ & $1.09[0.87,1.36]$ & & & \\
\hline Total events & 154 & & 142 & & & & & & \\
\hline \multicolumn{7}{|c|}{$\begin{array}{l}\text { Heterogeneity: } \mathrm{Ch}^{2}=0.64, \mathrm{df}=1(\mathrm{P}=0.42) ; \mathrm{I}^{2}=0 \% \\
\text { Test for overall effect: } \mathrm{Z}=0.72(\mathrm{P}=0.47)\end{array}$} & 0.2 & 0.5112 & \\
\hline
\end{tabular}

Figure 9. Forest plot of comparing stroke by TNK-t-PA vs. t-PA

\section{TIMI Grade Flow}

Of three studies $(28,32,33)$ on TIMI grade, two trials $(28,33)$ with TIMI grade 3 flow at 90 min and TIMI grade 2/3 flow at 90 min were incorporated in the meta-analysis. In total, the sample size of the two studies was 162 , and the results of the meta-analysis (Figure 10) revealed that the TIMI grade 3 flow at 90 min outcome was similar in both groups $(\mathrm{RR}=1.11$; 95\% CI: 0.89-1.37; $P=0.35)$.

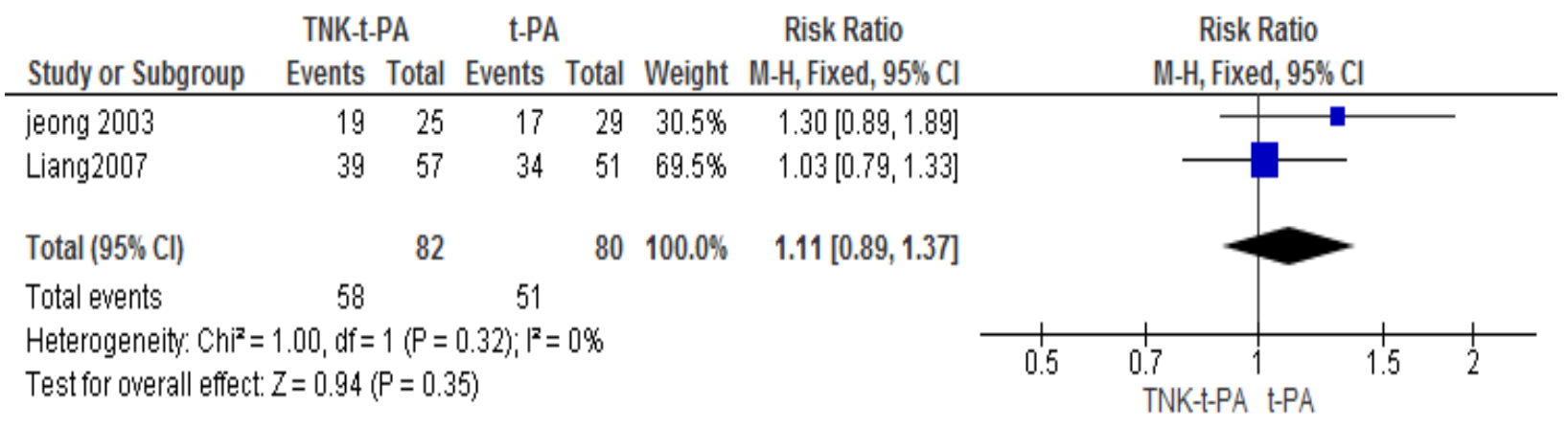




\section{Figure 10. Forest plot of comparing TIMI grade 3 flow at 90 min by TNK-t-PA vs. t-PA}

However, the combined results of the TIMI grade $2 / 3$ flow at $90 \mathrm{~min}$ in the meta-analysis indicated that the outcome was not similar in the two groups, with a statistically significant difference. In other words, evidence of TIMI grade 2/3 flow at 90 min was in favor of alteplase; patients receiving alteplase experienced better conditions than tenecteplase-receiving patients $(\mathrm{RR}=1.19 ; 95 \% \mathrm{CI}: 1.05-1.36 ; P=0.009)$ (Figure 11).

$\begin{array}{llll}\text { TNK-t-PA } & \text { t-PA } & \text { Risk Ratio } & \text { Risk Ratio }\end{array}$

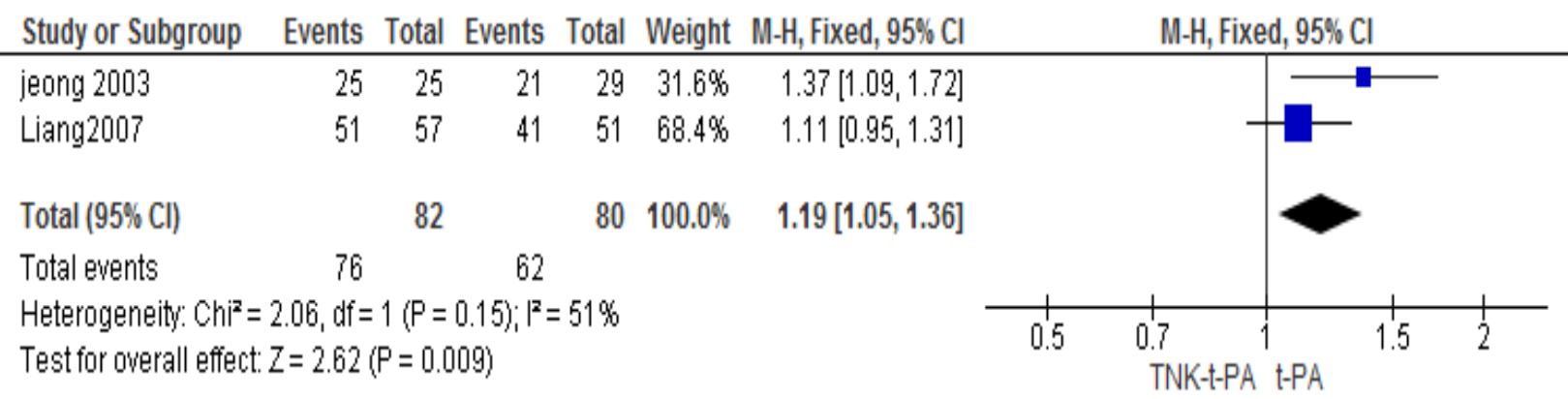

Figure 11. Forest plot of comparing TIMI grade $2 / 3$ flow at 90 min by TNK-t-PA vs. t-PA

\section{Other Outcomes}

Liang (2007) (28)also reported nonfatal cardiac events with rates of $10.3 \%$ and $11.54 \%$ for patients treated with tenecteplase and alteplase, respectively $(P=1)$, which were slightly different but not statistically significant. In other words, the observed value was similar for both groups. One study (31) also investigated the rate of vascular presentation for the two drugs, indicating that the rate of vasodilatation was better in patients treated with tenecteplase than those treated with alteplase, a difference that was significant $(P=0.04)$.

\section{Discussion}

Our meta-analysis showed that there were no significant differences between tenecteplase- and alteplase-treated patients in 30-day mortality, reinfarction, cardiogenic shock, ICH, stroke, or TIMI grade 3 flow at $90 \mathrm{~min}$. However, the TIMI grade $2 / 3$ flow at 90 min was not similar in the two groups, demonstrating a statistically significant difference. Patients receiving alteplase experienced better conditions than those treated with tenecteplase ( $\mathrm{RR}=1.19 ; 95 \% \mathrm{CI}: 1.05-1.36 ; P=0.009)$, which could be due to the small sample size $(n=162)$ for the meta-analysis.

Based on the findings of this meta-analysis, the tenecteplase group had a significantly better overall bleeding rate than alteplase group $(\mathrm{RR}=0.92 ; 95 \% \mathrm{CI}$ : 0.87-0.96; $P=0.0003)$. In other words, taking tenecteplase was associated with a lower rate of hemorrhage than alteplase. For major bleeding events, the results showed that major bleeding in the two groups receiving tenecteplase and alteplase was not the same, and the difference was to the benefit of tenecteplase recipients ( $\mathrm{RR}=0.79 ; 95 \% \mathrm{CI}$ : 0.69-0.99; $P=0.0002)$. In other words, the patients receiving tenecteplase were in better conditions than those receiving alteplase in terms of major bleeding. Also, two studies with 17,059 participants reporting minor bleeding were included in the meta-analysis. The results showed that minor bleeding was similar in the two groups receiving the drugs, and there was no significant difference $(\mathrm{RR}=0.95$; 95\% CI: 0.87-1.00; $P=0.06)$.

The results of our study differ from those of a systematic review by Marti et al. (34) on acute pulmonary embolism (34), which presented a lower risk of major bleeding in patients receiving alteplase $(\mathrm{OR}=1.07 ; 95 \% \mathrm{CI}: 0.43-0.2 .62 ; P<0.001)$ than those receiving tenecteplase $(\mathrm{OR}=5.02 ; 95 \% \mathrm{CI}$ : 2.72-9.29; $P<0.001)$. These differences are almost certainly due to the nature of the comparison and the inclusion of aging patients in the study groups using tenecteplase. Subgroup analysis in a study by Marti et al. (34) based on the thrombolytic agent suggested a lower risk of intracranial or fatal hemorrhage in studies using alteplase $(\mathrm{OR}=1.09 ; 95 \% \mathrm{CI}: 0.27-4.40 ; P=0.008)$ compared to tenecteplase (OR=7.32; 95\% CI: 1.64 32.63; $P=0.008)$. Similarly, Mehta et al. (35) in a metaanalysis reported that bolus treatment was associated with an increased risk of ICH compared with infusion.

Jinatongthai (36) showed that there was no significant difference in mortality risk between alteplase and tenecteplase. For major bleeding, a tenecteplase-based regimen tended to be associated with a lower risk of bleeding than other regimens $(\mathrm{RR}=0.79$ [95\% CI: 0.63-1.00]). Thelengana et al. (37) reported that there was no significant difference between tenecteplase and alteplase in excellent functional outcome at 90 days, good functional outcome at 90 days, and intracerebral hemorrhage, symptomatic intracerebral hemorrhage, or mortality at 90 days. This meta-analysis found that tenecteplase significantly favored one outcome (early major neurological improvement). Other outcomes (intracerebral hemorrhage and mortality at 90 days) did not differ between tenecteplase and alteplase groups. 
Also, Kheiri (38) showed that tenecteplase-treated patients had no increased risk of intracerebral hemorrhage or mortality compared with alteplasetreated patients. In summary, tenecteplase is not associated with significant differences in safety compared with alteplase, thus confirming our metaanalysis results. One study (39) suggested that tenecteplase does not differ from alteplase in its efficacy and safety while managing acute ischemic stroke. This study showed that the use of tenecteplase is clinically justified and is similar to alteplase in efficacy and safety.

However, the ease of use (only an intravenous bolus and with no maintenance infusion) could offer a benefit to tenecteplase over alteplase. In Iran, cardiovascular diseases are the most common causes of death, and the prevalence of AMI has increased in recent years (40). To restrain the rising trend of AMI, it is necessary to take preventive measures. In low-income countries such as Iran (with a high prevalence of AMI), the patient's compliance to alteplase may markedly decrease because of its heavy cost and lower availability than tenecteplase. Thus, tenecteplase can be a good alternative to alteplase for the treatment of AMI in low-income countries.

\section{Conclusion}

In the present meta-analysis, tenecteplase had similar clinical effectiveness and safety to alteplase and was probably superior in one outcome, i.e., major bleeding. Other outcomes did not differ between the tenecteplase and alteplase groups. In comparison with alteplase, tenecteplase is recommended due to its easier use and better safety in reducing the risk of bleeding.

\section{Ethical considerations}

Ethical issues (Including plagiarism, informed consent, misconduct, data fabrication and/or falsification, double publication and/or submission, redundancy, etc.) have been completely observed by the authors.

\section{Acknowledgments}

The authors thank all those who helped them writing this article.

\section{Conflict of Interest}

Authors declared no conflict of interest.

\section{References}

1. Tullmann DF, Haugh KH, Dracup KA, Bourguignon C. A randomized controlled trial to reduce delay in older adults seeking help for symptoms of acute myocardial infarction. Res

\section{Nurs Health. [DOI:10.1002/nur.20245] [PMID]}

2. Prabhakaran D, Jeemon P, Sharma M, et al. The changing patterns of cardiovascular diseases and their risk factors in the states of India: the Global Burden of Disease Study 1990-2016. Lancet Glob Health. 2018;6(12):e1339-e51.

3. Piegas LS, Avezum A, Pereira JC, et al. Risk factors for myocardial infarction in Brazil. Am Heart J. 2003;146(2):331-8. [DOI:10.1016/S0002-8703(03)00181-9]

4. Kannel WB. Contribution of the framingham study to preventive cardiology. J Am College Cardiol. 1990;15(1):206-11. [DOI:10.1016/0735-1097(90)90203-2]

5. Antman EM, Hand M, Armstrong PW, et al. 2007 focused update of the ACC/AHA 2004 guidelines for the management of patients with ST-elevation myocardial infarction: a report of the American College of Cardiology/American Heart Association Task Force on Practice Guidelines. J Am CollCardiol. 2008;51(2):21047. [DOI:10.1016/j.jacc.2007.10.001] [PMID]

6. Van De Werf F, Adgey J, Ardissino D, et al. Single-bolus tenecteplase compared with frontloaded alteplase in acute myocardial infarction: the ASSENT-2 double-blind randomised trial. Lancet (London, England). 1999;354(9180):716-22. [DOI:10.1016/S01406736(99)07403-6]

7. Howland RD, Mycek MJ, Harvey RA, Champe PC. Lippincott's illustrated reviews: Pharmacology: Lippincott Williams \& Wilkins Philadelphia; 2006.

8. O'Gara PT, Kushner FG, Ascheim DD, et al. 2013 ACCF/AHA guideline for the management of ST-elevation myocardial infarction: a report of the American College of Cardiology Foundation/American Heart Association Task Force on Practice Guidelines. Circulation. 2013;127(4):e362-425.

9. Aasa M, Henriksson M, Dellborg M, et al. Cost and health outcome of primary percutaneous coronary intervention versus thrombolysis in acute ST-segment elevation myocardial infarction-results of the Swedish early decision reperfusion study (SWEDES) trial. Am Heart J. 2010;160(2):322-8.

\section{[DOI:10.1016/j.ahj.2010.05.008] [PMID]}

10. Efficacy and safety of tenecteplase in combination with enoxaparin, abciximab, or unfractionated heparin: the ASSENT-3 randomised trial in acute myocardial infarction. Lancet (London, England). 2001;358(9282):605-13. [DOI:10.1016/S01406736(01)05775-0] 
11. Ng S, Lim T, Tan S, Yap R, Tay E. Comparison of efficacy and safety of streptokinase and tenecteplase in patients with ST-segment elevated acute myocardial infarction (STEMI) in Melaka Hospital. Proceedings of the 9th National Pharmacy R\&D Conference; 2016.

12. Tourani S, Bashzar S, Nikfar S, Ravaghi H, Sadeghi M. Effectiveness of tenecteplase versus streptokinase in treatment of acute myocardial infarction: a meta-analysis. Tehran Univ Med J. 2018;76(6):380-7.

13. Yusuf S, Collins R, Peto R, et al. Intravenous and intracoronary fibrinolytic therapy in acute myocardial infarction: overview of results on mortality, reinfarction and side-effects from 33 randomized controlled trials. Europ Heart J. 1985;6(7):556-85.

[DOI:10.1093/oxfordjournals.eurheartj.a061905 ] [PMID]

14. Trialists FT. Indications for fibrinolytic therapy in suspected acute myocardial infarction: collaborative overview of early mortality and major morbidity results from all randomised trials of more than 1000 patients. Lancet. 1994;343(8893):311-22. [DOI:10.1016/S01406736(94)91161-4]

15. Llevadot J, Giugliano RP, Antman EM. Bolus fibrinolytic therapy in acute myocardial infarction. JAMA. 2001;286(4):442-9. [DOI:10.1001/jama.286.4.442] [PMID]

16. Wilcox RG. Clinical trials in thrombolytic therapy: what do they tell us? INJECT 6-month outcomes data. Am J Cardiol. 1996;78(12):20-3. [DOI:10.1016/S0002-9149(96)00739-4]

17. Walley T, Dundar Y, Hill R, Dickson R. Superiority and equivalence in thrombolytic drugs: an interpretation. QJM. 2003;96(2):15560. [DOI:10.1093/qimed/hcg020] [PMID]

18. Investigators G. An international randomized trial comparing four thrombolytic strategies for acute myocardial infarction. New Eng J Med. 1993;329(10):673-82.

[DOI:10.1056/NEJM199309023291001] [PMID]

19. Taylor GJ, Moses HW, Koester D, et al. A difference between front-loaded streptokinase and standard-dose recombinant tissue-type plasminogen activator in preserving left ventricular function after acute myocardial infarction (the Central Illinois Thrombolytic Therapy Study). Am J Cardiol. 1993;72(14):1010-4. [DOI:10.1016/00029149(93)90854-6]

20. Cherng WJ, Chiang CW, Kuo CT, Lee CP, Lee YS. A comparison between intravenous streptokinase and tissue plasminogen activator with early intravenous heparin in acute myocardial infarction. Am Heart J. 1992;123(4):841-6. [DOI:10.1016/00028703(92)90685-O]

21. Verstraete M, Bory M, Collen D, et al. Randomised trial of intravenous recombinant tissue-type plasminogen activator versus intravenous streptokinase in acute myocardial infarction: report from the European Cooperative Study Group for Recombinant Tissue-type Plasminogen Activator. Lancet. 1985;325(8433):842-7. [DOI:10.1016/S01406736(85)92208-1]

22. Della GIPLS, Miocardico SNI. Effectiveness of intravenous thrombolytic treatment in acute myocardial infarction. Lancet (London, England). 1986;1:397.

23. Baigent C, Collins R, Appleby P, Parish S, Sleight P, Sleight R. ISIS-2 (Second International Study of Infarct Survival) Collaborative Group. Randomized trial of intravenous streptokinase, oral aspirin, both, or neither among 17,187 cases of suspected acute myocardial infarction: ISIS-2. Lancet. 1988;2:349-60. [DOI:10.1016/S01406736(88)92833-4]

24. Teo KK, Yusuf S, Collins R, Held PH, Peto R. Effects of intravenous magnesium in suspected acute myocardial infarction: overview of randomised trials. BMJ. 1991;303(6816):1499503. [DOI:10.1136/bmj.303.6816.1499] [PMID] [PMCID]

25. Collins R, Peto R, Flather M, et al. ISIS-4-A randomised factorial assessing early oral captopril, oral mononitrate, and intravenous magnesium sulphate in 58.050 patient with suspected acute myocardial-infarction. Lancet. 1995;345(8951):669-85. [DOI:10.1016/S01406736(95)90865-X]

26. Collins R, Peto R, Parish S, Sleight P. ISIS-3 and GISSI-2: no survival advantage with tissue plasminogen activator over streptokinase, but a significant excess of strokes with tissue plasminogen activator in both trials. Am J Cardiol. 1993;71(12). [DOI:10.1016/00029149(93)90591-Y]

27. White HD, Rivers JT, Maslowski AH, Ormiston JA, Takayama M, Hart HH, et al. Effect of intravenous streptokinase as compared with that of tissue plasminogen activator on left ventricular function after first myocardial infarction. New England Journal of Medicine. 1989;320(13):817-21.

[DOI:10.1056/NEJM198903303201301] [PMID]

28. Liang F, Hu D, Shi X, Gao M, Wei J, Zhao H, et al. Efficacy and safety of single-bolus 
tenecteplase compared with front-loaded alteplase in Chinese patients with acute myocardial infarction. J GeriatrCardiol. 2007;4(3):137-41.

29. Van de Werf F, Barron H, Armstrong P, Granger C, Berioli S, Barbash $\mathrm{G}$, et al. Incidence and predictors of bleeding events after fibrinolytic therapy with fibrin-specific agents. A comparison of TNK-tPA and rt-PA. European heart journal. 2001;22(24):2253-61. [DOI:10.1053/euhj.2001.2686] [PMID]

30. Sinnaeve P, Alexander J, Belmans A, Bogaerts $\mathrm{K}$, Langer A, Diaz R, et al. One-year follow-up of the ASSENT-2 trial: a double-blind, randomized comparison of single-bolus tenecteplase and front-loaded alteplase in 16,949 patients with ST-elevation acute myocardial infarction. American heart journal. 2003;146(1):27-32. [DOI:10.1016/S0002$\underline{8703(03) 00117-0]}$

31. Binbrek AS, Rao NS, Neimane D, Hatou E, Abdulali S, Sobel BE. Comparison of rapidity of coronary recanalization in men with tenecteplase versus alteplase in acute myocardial infarction. The American journal of cardiology. 2004;93(12):1465-8.

[DOI:10.1016/j.amjcard.2004.03.004] [PMID]

32. Cannon CP, Gibson CM, McCabe $\mathrm{CH}$, et al. TNK-tissue plasminogen activator compared with front-loaded alteplase in acute myocardial infarction: results of the TIMI 10B trial. Circulation. 1998;98(25):2805-14. [DOI:10.1161/01.CIR.98.25.2805] [PMID]

33. Jeong MH, Kim W, Kang JC, et al. A comparison of tenecteplase (TNK-tPA) and alteplase (rt-PA) in korean patients with acute myocardial infarction (a randomized, multi-centered coronary angiographic trial). Korean Circ J. 2003;33(5):362-73.

[DOI:10.4070/kcj.2003.33.5.362]

34. Marti C, John G, Konstantinides S, et al. Systemic thrombolytic therapy for acute pulmonary embolism: a systematic review and meta-analysis. Eur Heart J. 2015;36(10):605-14. [DOI:10.1093/eurheartj/ehu218] [PMID] [PMCID]

35. Mehta SR, Eikelboom JW, Yusuf S. Risk of intracranial haemorrhage with bolus versus infusion thrombolytic therapy: a meta-analysis. Lancet. 2000;356(9228):449-54. [DOI:10.1016/S0140-6736(00)02552-6]

36. Jinatongthai P, Kongwatcharapong J, Foo CY, et al. Comparative efficacy and safety of reperfusion therapy with fibrinolytic agents in patients with ST-segment elevation myocardial infarction: a systematic review and network meta-analysis. Lancet. 2017;390(10096):74759. [DOI:10.1016/S0140-6736(17)31441-1]

37. Thelengana A, Radhakrishnan DM, Prasad M, Kumar A, Prasad K. Tenecteplase versus alteplase in acute ischemic stroke: systematic review and meta-analysis. ActaneurolBelgica. 2019;119(3):359-67. [DOI:10.1007/s13760018-0933-9] [PMID]

38. Kheiri B, Osman M, Abdalla A, et al. Tenecteplase versus alteplase for management of acute ischemic stroke: a pairwise and network meta-analysis of randomized clinical trials. J ThrombThrombol. 2018;46(4):440-50. [DOI:10.1007/s11239-018-1721-3] [PMID]

39. Nepal G, Kharel G, Ahamad ST, Basnet B. Tenecteplase versus alteplase for the management of acute ischemic stroke in a lowincome country-Nepal: Cost, Efficacy, and Safety. Cureus. 2018;10(2):e2178. [DOI:10.7759/cureus.2178]

40. Mohseni J, Kazemi T, Maleki MH, Beydokhti H. A Systematic review on the prevalence of acute myocardial infarction in Iran. Heart Views. 2017;18(4):125-32. [DOI:10.4103/HEARTVIEWS.HEARTVIEWS 71_17] [PMID] [PMCID]

\section{How to Cite This Article:}

Bashzar S, Nikfar S, Sabermahani A. A Systematic Review and Meta-Analysis of the Safety and Effectiveness of Tenecteplase Versus Alteplase in Treatment of Patients with ST-Elevation Myocardial Infarction. J Adv Med Biomed Res. 2020; 28 (130):265-275

\section{Download citation:}

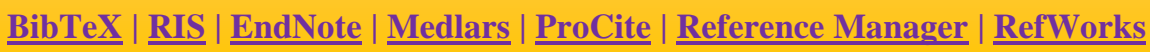

\section{Send citation to:}

$$
\text { Mendeley } 2 \text { Zotero } \text { (i) RefWorks } \underline{\text { RefWorks }}
$$

